This item was submitted to Loughborough's Research Repository by the author.

Items in Figshare are protected by copyright, with all rights reserved, unless otherwise indicated.

\title{
A novel FSS for gain enhancement of printed antennas in UWB frequency spectrum
}

PLEASE CITE THE PUBLISHED VERSION

https://doi.org/10.1002/mop.30789

PUBLISHER

Wiley

VERSION

AM (Accepted Manuscript)

\section{PUBLISHER STATEMENT}

This work is made available according to the conditions of the Creative Commons Attribution-NonCommercialNoDerivatives 4.0 International (CC BY-NC-ND 4.0) licence. Full details of this licence are available at: https://creativecommons.org/licenses/by-nc-nd/4.0/

\section{LICENCE}

CC BY-NC-ND 4.0

\section{REPOSITORY RECORD}

Tahir, Farooq A., Talha Arshad, Sadiq Ullah, and James A. Flint. 2019. "A Novel FSS for Gain Enhancement of Printed Antennas in UWB Frequency Spectrum”. figshare. https://hdl.handle.net/2134/26507. 


\title{
A Novel FSS for Gain Enhancement of UWB Printed Antennas
}

\author{
Farooq A. Tahir ${ }^{1}$, Talha Arshad ${ }^{1}$, Sadiq Ullah ${ }^{2}$, James A. Flint ${ }^{3}$ \\ ${ }^{1}$ Research Institute for Microwave and Millimeter-wave Studies (RIMMS), National University of \\ Sciences and Technology, Islamabad, Pakistan \\ ${ }^{2}$ Department of Telecommunication Engineering, University of Engineering \& Technology, Peshawar, \\ Charsadda Road, Mardan, 23200, Pakistan \\ ${ }^{3}$ School of Mechanical, Electrical and Manufacturing Engineering, Loughborough University, LE11 \\ 3TU, United Kingdom \\ Corresponding author: farooq.tahir@seecs.edu.pk \\ Received 03 March 2017
}

\begin{abstract}
This paper presents a novel compact unilayer frequency selective surface (FSS) to enhance the gain of an Ultra-Wideband (UWB) monopole antenna. The proposed FSS unit cell consists of simple metallic patterns printed on both sides of $14 \times 14 \mathrm{~mm}^{2}$ FR4 substrate. The proposed FSS has very low transmission co-efficient and linearly decreasing reflection phase over the bandwidth of $9 \mathrm{GHz}$ (3 to12 GHz), which makes it suitable candidate to provide in-phase reflection for UWB antennas. The gain of the proposed composite antenna is $8.9 \mathrm{~dB}$ which is improved by $4 \mathrm{~dB}$ relative to the conventional counterpart.
\end{abstract}

Keywords: Frequency selective surface, UWB, high gain, FSS reflector, gain enhancement

\section{INTRODUCTION}

Ultra-wideband (UWB) technology, being low-power and wideband, has found great applications for short range and high speed communications such as Personal Area Networks (PANs), Body Area Networks (BANs), sensor networks, medical imaging, road-safety, search and rescue systems, life-jacket, landmine detection, UWB pulse radars and smart homes [1], to name a few. The very low power spectral density assigned to UWB technology (typically less than $-40 \mathrm{dBm}$ ), where on one side, makes it ideal for short-range communications, on the other side, it needs relatively high gain antennas with very stable radiation characteristics [ref].

Printed antennas, particularly monopole [2] and slot [3], are extensively being used in ultra-wideband electronic devices due to their compact size, low profile, low fabrication cost, and ultra-wide impedance bandwidth. However, these antennas, when mounted near metallic surfaces and electronic objects inside handheld communication devices suffer from severe impedance mismatch. Moreover, these low profile antennas inherently exhibit low gain and poor directivity particularly at lower frequencies [4]. In certain applications where line-of- 
sight communication is critical such as microwave medical imaging, see-through-wall radars and under-rubble radars, UWB antennas with high directivity are required. Properly designed Frequency Selective Surfaces (FSSs) can potentially improve the directivity of printed UWB antennas as well as shield the electronics beneath them. FSS decouples the antenna and the nearby metallic surfaces allowing the mounting of planar antenna very close to the metallic surfaces thus increasing overall system compactness. FSSs are periodic structures, which are constructed by the repetition of a pre-designed unit cell. They act as spatial filters and can be designed to permit electromagnetic (EM) waves to pass through them (band pass FSS) or reflect them (band stop FSS) depending on their specific unit cell structure, operating frequency and polarization of the incoming EM wave. FSSs can be designed to have ultrawide stopband making them suitable to act as reflectors for UWB antennas. In addition, FSSs can control the phase of the reflected wave to ensure constructive interference at the antennaplane through in phase reflection.

Along with the above potential benefits, large size and narrow bandwidth are the two main limitations of frequency selective surfaces. Being periodic in nature, it is not easy to realize a compact FSS with single substrate layer exhibiting ultra-wideband characteristics [5]. However, ultra-wideband response can be easily achieved through multilayer FSSs but at the cost of increase in the overall volume and size.

In recent literature, several multi-layer as well as single-layer FSS designs for UWB applications are presented [4-10]. A two-layer FSS with unit cell consisting of a modified cross-loop is presented in [7]. It provides bandwidth of $122 \%(3-14 \mathrm{GHz}$ ) and gainenhancement of around $4 \mathrm{~dB}$, the main disadvantage of this design is its large unit cell size $\left(17 \times 17 \mathrm{~mm}^{2}\right)$ and increased overall volume of the multi-layer structure. A two-layer and a four layer FSS structures are presented in [8] and [9] respectively. Though, these multilayer FSSs provide ultrawideband response, yet their practical application in modern communication devices is limited due to their increased size and bulkiness. To avoid bulky volumes, the FSS must be designed on single substrate layer yet it should exhibit broad frequency response. Moreover, single-layer FSS offers advantage of easy integration inside modern portable electronics and communication devices. In [10], a very large percentage bandwidth of $102 \%$ (3.9-11.10 GHz) with a single-layer FSS is achieved; however the lower frequency response is very poor not covering the critical part of UWB band from 3.1-3.9 GHz. In [4], a single layer FSS consisting of crossed-loops is presented. It achieved bandwidth of only $52 \%(7-11.78 \mathrm{GHz})$ with unit cell size of $15 \times 15 \mathrm{~mm}^{2}$.

In this article, the author presents a single-layer FSS with ultra-wide stop band characteristics. The geometry of the unit cell is simple and therefore easy to fabricate. The physical size of the FSS unit cell is $16 \mathrm{~mm} \times 16 \mathrm{~mm}$. Electrical dimensions of the unit cell is $0.14 \lambda \times 0.14 \lambda$, where $\lambda$ refers to the wavelength of the lowest operating frequency of $3 \mathrm{GHz}$. Along with compact size and single-layer structure, the proposed FSS exhibits excellent stop band characteristics in the whole UWB band (3-12 GHz). Moreover, as a test case, the designed FSS is applied as a reflector for a monopole UWB antenna. A significant gain improvement of up to $4 \mathrm{~dB}$ is achieved. 


\section{FSS DESIGN}

The response of a frequency selective surface entirely depends on the design of its unit cell. The geometry of the proposed FSS unit cell is shown in Fig. 1(a). It is designed on an inexpensive dielectric substrate FR4 with dielectric constant 4.4, thickness $1.57 \mathrm{~mm}$ and loss tangent 0.02. The proposed FSS unit cell consists of three metallic strips connecting the two metallic rectangles. The same metallic pattern is printed on both sides of the FR4 substrate as shown in Figure 1(b). Overall physical dimensions of the unit cell are $14 \mathrm{~mm} \times 14 \mathrm{~mm}$.

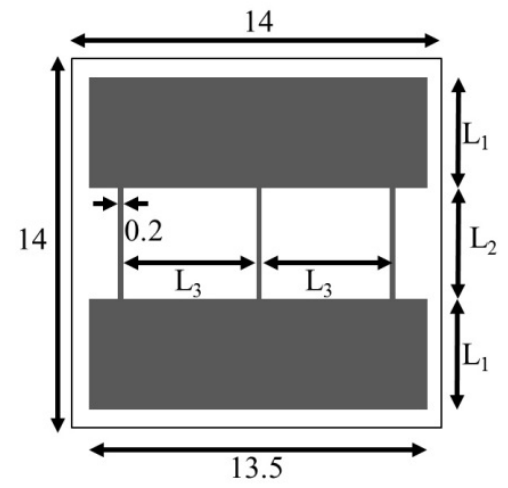

(a)

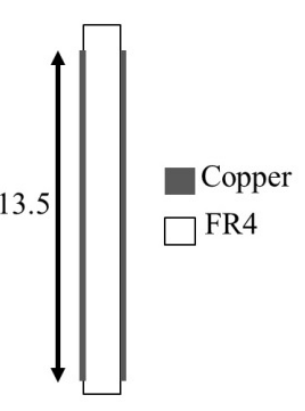

(b)

Fig. 1. Geometry of FSS unit cell (a) Front view and (b) side view with dimensions: $L_{1}=L_{2}=$ 4.5 and $\mathrm{L}_{3}=6$. Units are in $\mathrm{mm}$.

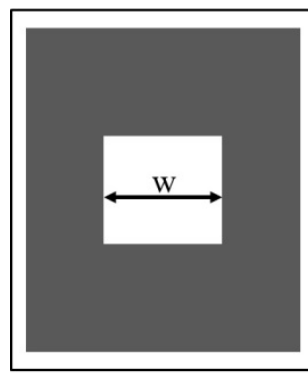

(a)

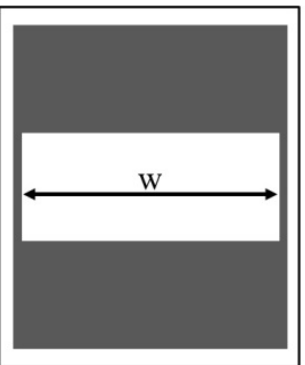

(b)

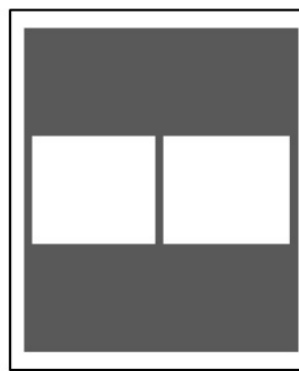

(c)

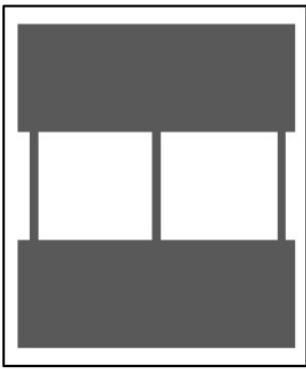

(d)

Fig. 2. Evolution of FSS unit cell (a) Conventional loop structure (b) Conventional loop structure with wide slot (c) Modified loop structure (d) Modified loop structure with offset strips

Design stages of the proposed FSS and their corresponding simulated $\left|S_{21}\right|$ results are shown in Fig. 2 and Fig. 3 respectively. The unit cell designed in $1^{\text {st }}$ stage (Fig. 2(a)) is based on conventional loop structure (CLS). The size of CLS is $14 \mathrm{~mm} \times 14 \mathrm{~mm}$ with inner slot having dimensions of $4.5 \mathrm{~mm} \times 4.5 \mathrm{~mm}$. The response of this CLS printed on both sides of the substrate is shown in Fig. 3. A bandwidth of $8.58 \mathrm{GHz}$ from $4.42-13 \mathrm{GHz}$ with $S_{21}<-10$ $\mathrm{dB}$ is achieved. The stopband response of CLS is poor in the lower part of UWB spectrum from 3-4 GHz. 


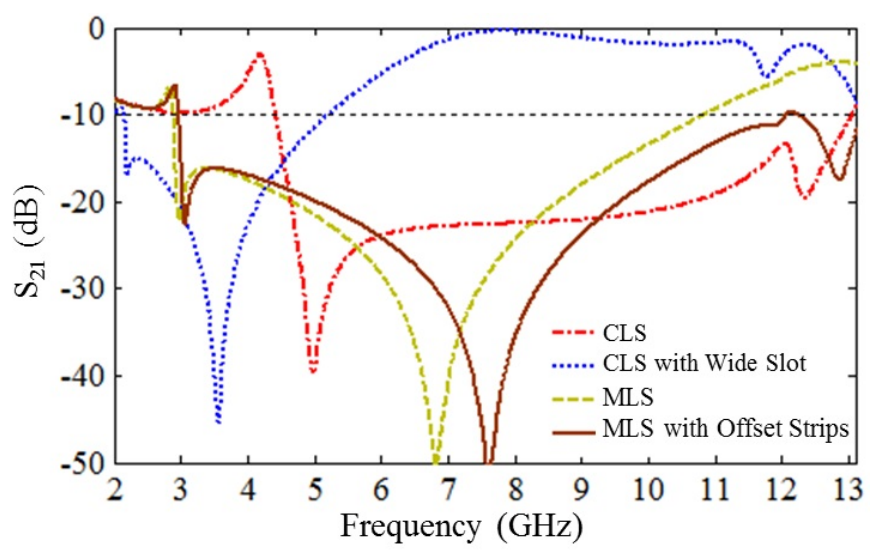

Fig. 3. Simulated transmission coefficient magnitude $\left(\mathrm{S}_{21}\right)$ of the FSSs shown in Fig. 2.

The first resonance and overall bandwidth of CLS depends on the total size of the unit cell and the width $(w)$ of the inner slot. Large size of both the unit cell and the slot width results in the lower values of the first resonace. Therefore, at the $2^{\text {nd }}$ step shown in Fig. 2(b), the slot-width of CLS is maximally increased $(w=13.1 \mathrm{~mm})$ to achieve first resonance at lower frequencies. $|\mathrm{S} 21|$ results in Fig. 3 show that the bandwidth of $3 \mathrm{GHz}$ from 2.2-5.2 $\mathrm{GHz}$ is achieved in the lower band. The stopband of this FSS at lower frequencies is good. Contrary to this the stopband bandwidth is badly degraded at higher frequencies, because wider slots limits the bandwidth at higher frequencies.

In $3^{\text {rd }}$ step, a metallic strip at the center of the slot is introduced as shown in Fig. 2 (c). The design of this modified loop structure (MLS) is such that the two smaller loops are formed within the main loop structure (LS). These smaller loops are responsible to broaden the overall frequency response. MSL achieves bandwidth of $7.8 \mathrm{GHz}$ from 2.9-10.7 GHz. To further increase the bandwidth of the unit cell towards higher frequencies, the overall width (w) of the slot is reduced by shifting the outer strips of MLS a little bit inwards as shown in Fig. 2 (d). As expected the lowest operating frequency is shifted a little bit from 2.9 to $3 \mathrm{GHz}$, however the bandwidth towards the upper end is significantly improved as compared to the MSL. With this design, bandwidth of $9 \mathrm{GHz}$ (3-12 GHz) is achieved.

The reflection phase $\left(S_{11}\right)$ is another important performance criterion for the FSSs particularly for the ones to be used in antenna gain enhancement application. The phase of the FSS should linearly decrease to provide in-phase reflection to the antennas [5]. The proposed FSS achieves a linearly decreasing phase form 3-12 GHz (Fig. 4).

To better understand the behavior of the proposed FSS, parametric analysis has been conducted. Distances among the three strips and the length of the strips play a key role in optimizing the stopband. Parameter $\mathrm{L}_{2}$, as depicted in Fig. 1, represents the length of the strips. We start the parametric study by varying $\mathrm{L}_{2}$ while keeping the parameter $\mathrm{L}_{3}$ constant to $6 \mathrm{~mm}$. Fig. 5 shows the simulated $S_{21}$ magnitude of the FSS with different lengths of $L_{2}$. The transmission band shifts towards the higher side as we increase $\mathrm{L}_{2}$. The best stopband at higher frequencies is achieved when $\mathrm{L}_{2}$ is optimized to $4.5 \mathrm{~mm}$. Further increase in the value $\mathrm{L}_{2}$ deteriorates this bandwidth. 


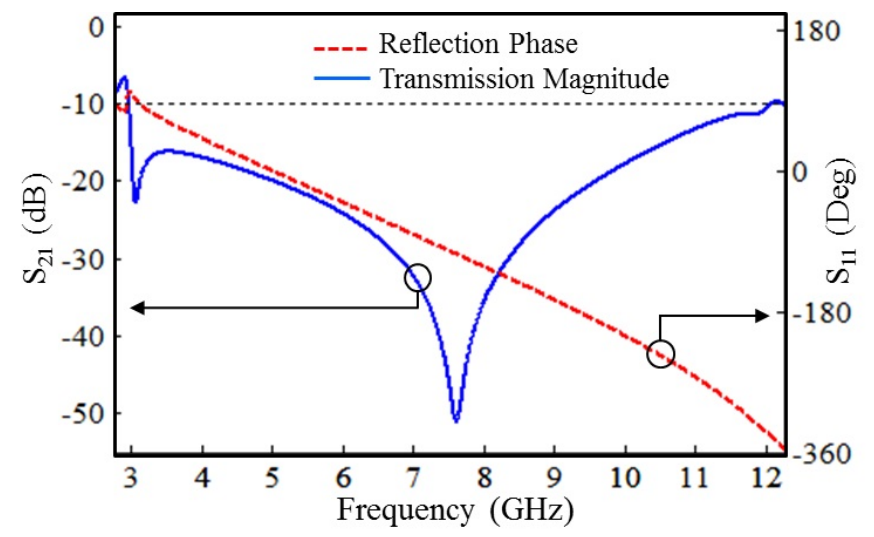

Fig. 4. Simulated transmission coefficient magnitude $\left(S_{21}\right)$ and reflection phase $\left(S_{11}\right)$ of the proposed FSS over UWB

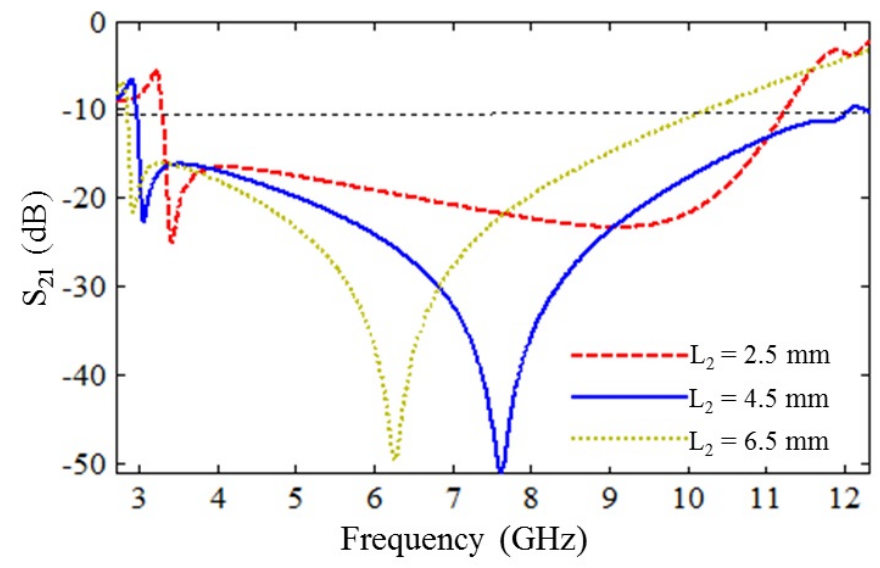

Fig. 5. Simulated transmission coefficient magnitude $\left(S_{21}\right)$ of the FSS with different values of $\mathrm{L}_{2}$

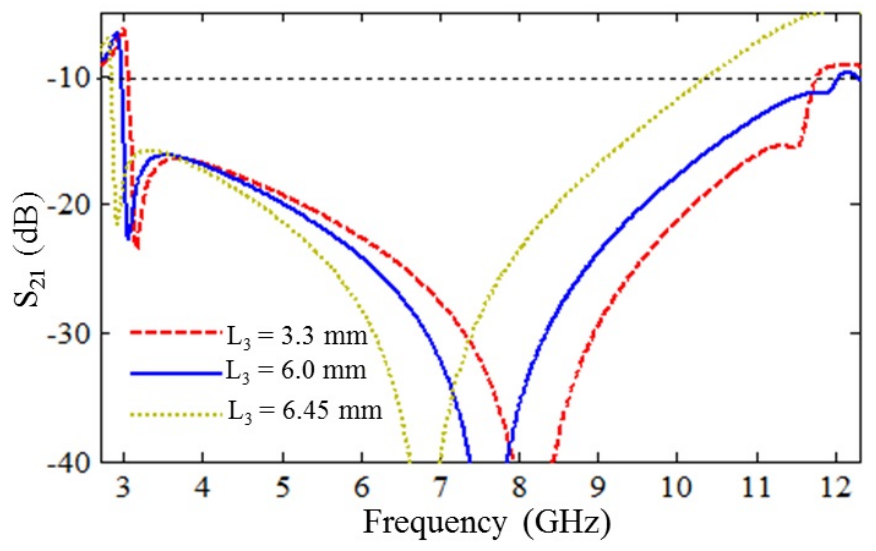

Fig. 6. Simulated transmission coefficient magnitude $\left(S_{21}\right)$ of the FSS with different values of $L_{3}$.

Fig. 6 shows the simulated $S_{21}$ magnitude of the FSS with different lengths of $L_{3}$ when both $L_{1}$ and $L_{2}$ are set to $4.5 \mathrm{~mm}$. $L_{3}$ is the distance between the center strip and outer strips. From Fig. 6, we can see that as $L_{3}$ increases (by shifting both the outer strips towards the 
ends) from $3.3 \mathrm{~mm}$ to $6 \mathrm{~mm}$ there is an improvement in the bandwidth particularly at lower frequencies. The bandwidth is the best when $\mathrm{L}_{3}$ is optimized to $6 \mathrm{~mm}$. When we set $\mathrm{L}_{3}$ equal to its maximum value of $6.45 \mathrm{~mm}$, the bandwidth deteriorates and the highest operating frequency is reduced to $10.4 \mathrm{GHz}$.

\section{UWB ANTENNA WITH THE FSS}

To test the gain enhancing ability of the FSS, a simple UWB monopole antenna is designed. Geometry of the antenna is shown in Fig. 7(a). Tapering of the transmission line and radiating patch is applied to achieve the impedance bandwidth for VSWR $<2$ over the UWB frequency band.

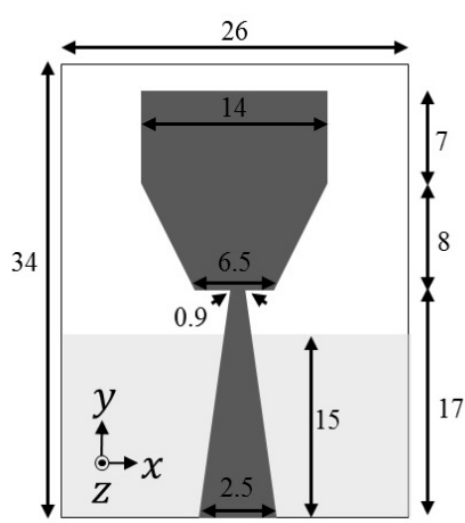

(a)

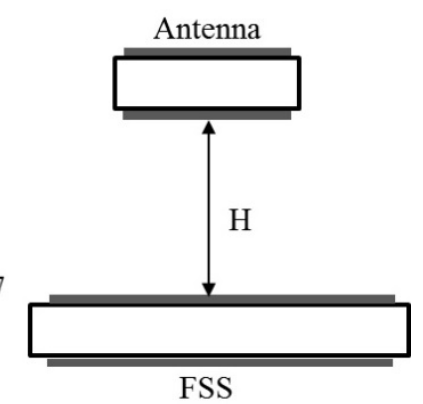

(b)

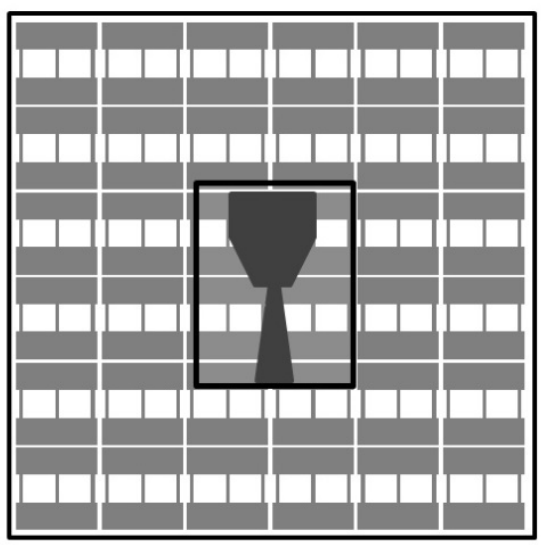

(c)

Fig. 7. (a) Geometry of the proposed UWB monopole antenna. Units are in mm. (b) Configuration of UWB antenna with the proposed FSS view from side and (c) top.

Fig. 7(b) shows the configuration of the UWB antenna with the proposed FSS array. An array of 36 elements $(6 \times 6)$ is constructed by repetition of the unit cell along $x$-axis and $y$ axis as shown in Fig. 7(c). The FSS is placed below the antenna so that it can reflect back radiations from the antenna. If, at the antenna plane, the reflected waves by the FSS are in phase with the radiated waves by the antenna then the directivity and front-to-back ratio of the UWB antenna is increased. The phase of the antenna's radiated wave towards FSS increases 
with the increase in frequency. The phase of the reflected waves must then decrease with the increase in the frequency to ensure constructive interference at the antenna plane. The simulated reflection phase in Fig. 4, predicts a linearly decreasing reflection phase of the FSS. Hence, the proposed FSS is well-matched to manipulate the phase of the reflected waves, thus ensuring constructive interference at the antenna plane. Height between the FSS and the antenna is an important factor for determining the condition of constructive interference; it is approximated by the following equation:

$$
\varphi_{F S S}-2 \beta H=2 n \pi \quad n=\cdots-2,-1,0,1 \ldots
$$

Where, $\varphi_{F S S}$ is the reflection phase introduced by the FSS, $H$ is the height between the FSS reflector and the antenna and $\beta$ is the propagation constant in free space. When $H$ is set equal to $\lambda / 2$, where $\lambda$ is the wavelength corresponding to the frequency at which the reflected phase $\varphi_{F S S}$ is zero, then both sides of Eq. (1) becomes equal. The reflection phase of the FSS crosses zero at $5 \mathrm{GHz}$. So to satisfy Eq. (1), the value of $H$ is calculated to be $30 \mathrm{~mm}(\lambda / 2)$.

\section{FABRICATION AND MEASUREMENTS}

The proposed UWB antenna and the FSS array are fabricated on FR4 substrate as shown in Fig 8. Gain of the antenna with FSS reflector is measured with in-house NSI Anechoic Chamber facility. Agilent Technologies E8362B Vector Network Analyzer is used to measure VSWR of the antenna

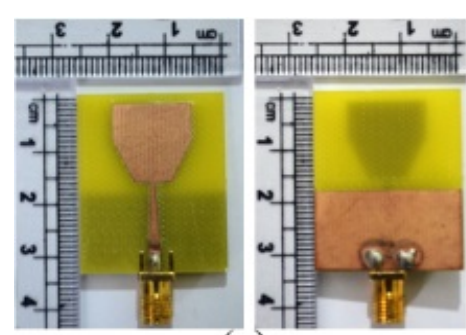

(a)

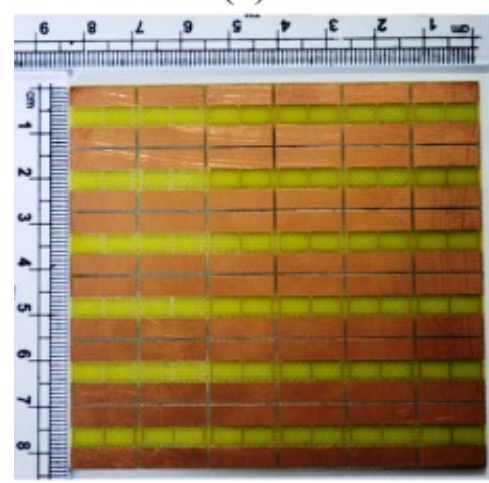

(b)

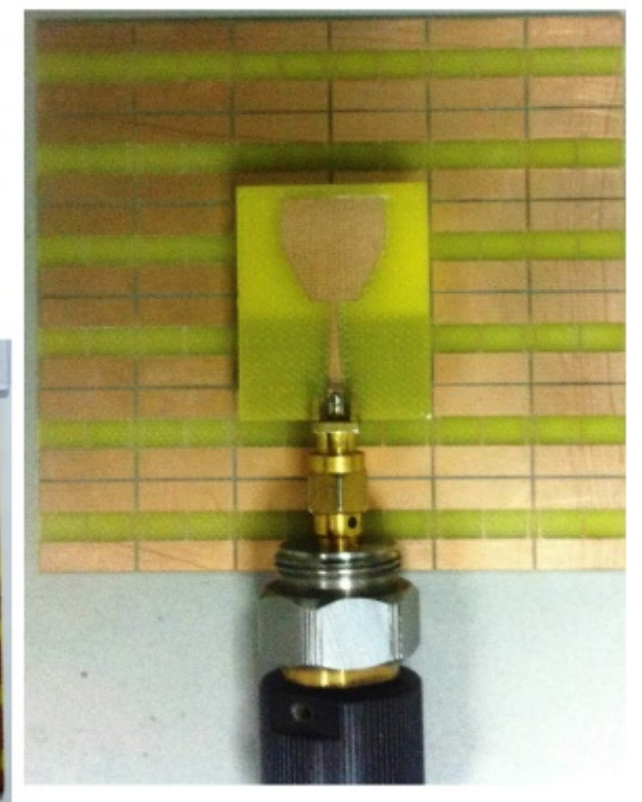

(c)

Fig. 8. Fabricated prototypes. (a) Antenna. (b) FSS. (c) Antenna with FSS.

The measured VSWR of the UWB antenna with and without FSS is shown in Fig. 9. The impedance bandwidth of UWB antenna is 2.8-14.2 GHz. When FSS is placed below the 
UWB antenna, there is slight change in its bandwidth due to current changes on the antenna surface caused by reflections from the FSS. Height between the antenna and FSS is optimized to $27 \mathrm{~mm}$ (approx. $\lambda / 2$ at $5 \mathrm{GHz}$ ) to ensure maximum impedance bandwidth for UWB antenna with the FSS. The impedance bandwidth of UWB antenna with the FSS is from $2.7-13.9 \mathrm{GHz}$ showing no significant deterioration in the input impedance of the UWB antenna with the FSS. For comparison, the VSWR for $H=15 \mathrm{~mm}$ is also measured and shown in Fig. 10. In this case the antenna composite bandwidth significantly reduces at lower UWB frequencies concluding that the distance between the antenna and FSS $(\mathrm{H})$ should be selected carefully to satisfy Eq. (1).

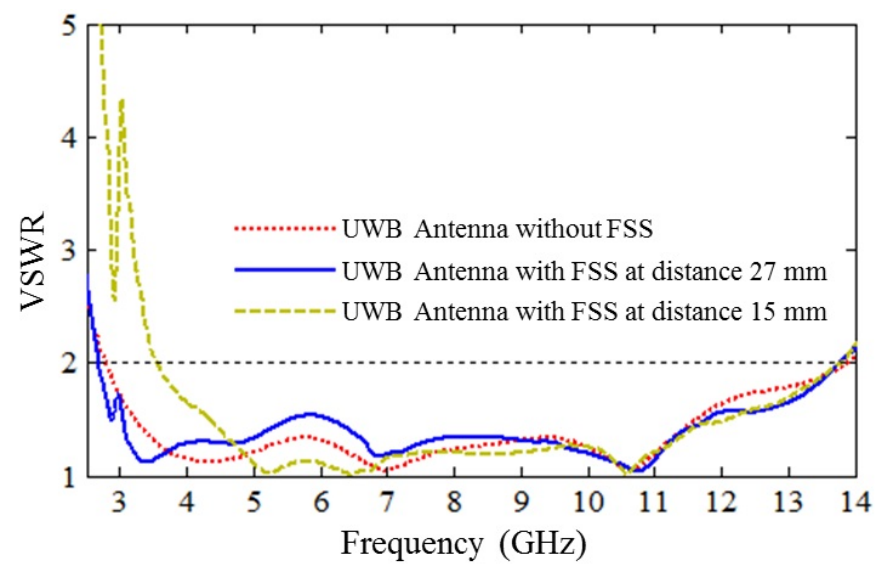

Fig. 9. Measured VSWR of the UWB antenna with and without the FSS.

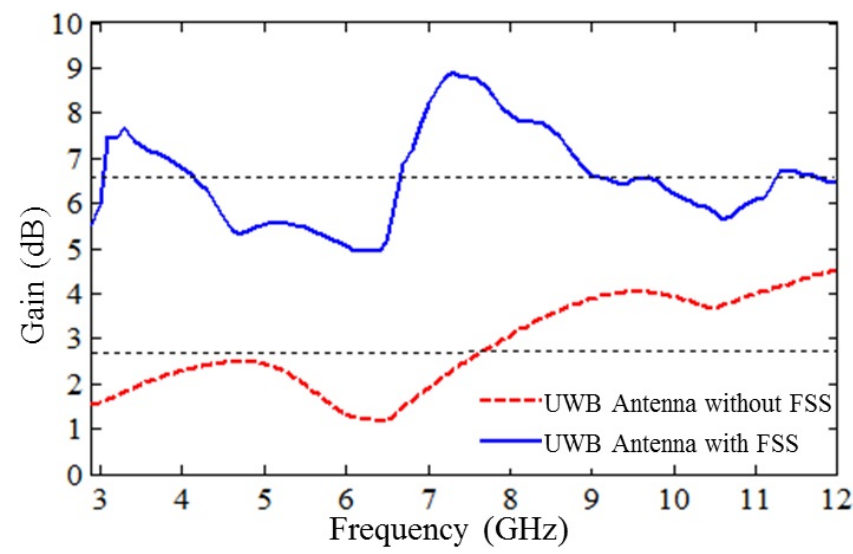

Fig. 10. Peak gain measurements of the UWB antenna with and without the FSS.

The peak gain of UWB monopole antenna without FSS (in free space), as shown in Fig. 10, varies with frequency. The average gain of the antenna is $2.8 \mathrm{dBi}$. When the FSS is placed below the antenna, the average gain of the antenna is improved to $6.6 \mathrm{dBi}$. Alternatively, there is gain improvement of $3.8 \mathrm{dBi}$ due to the FSS. Highest gain improvement occurs around $3.1 \mathrm{GHz}$, where FSS improves antenna gain by $5.7 \mathrm{dBi}$. The peak gain of 8.9 $\mathrm{dBi}$ for the antenna composite is achieved at $7.3 \mathrm{GHz}$. Application of the FSS greatly improves the gain of the antenna. Fig. 11 shows the measured radiation patterns of the UWB antenna with and without FSS at $3.5 \mathrm{GHz}$ and $7.5 \mathrm{GHz}$. The antenna has nearly 
omnidirectional pattern in $x z$ plane (H-plane) and bidirectional in $y z$ plane (E-plane). The point to be noted is that the radiation patterns become more directional for the FSS backed UWB antenna.
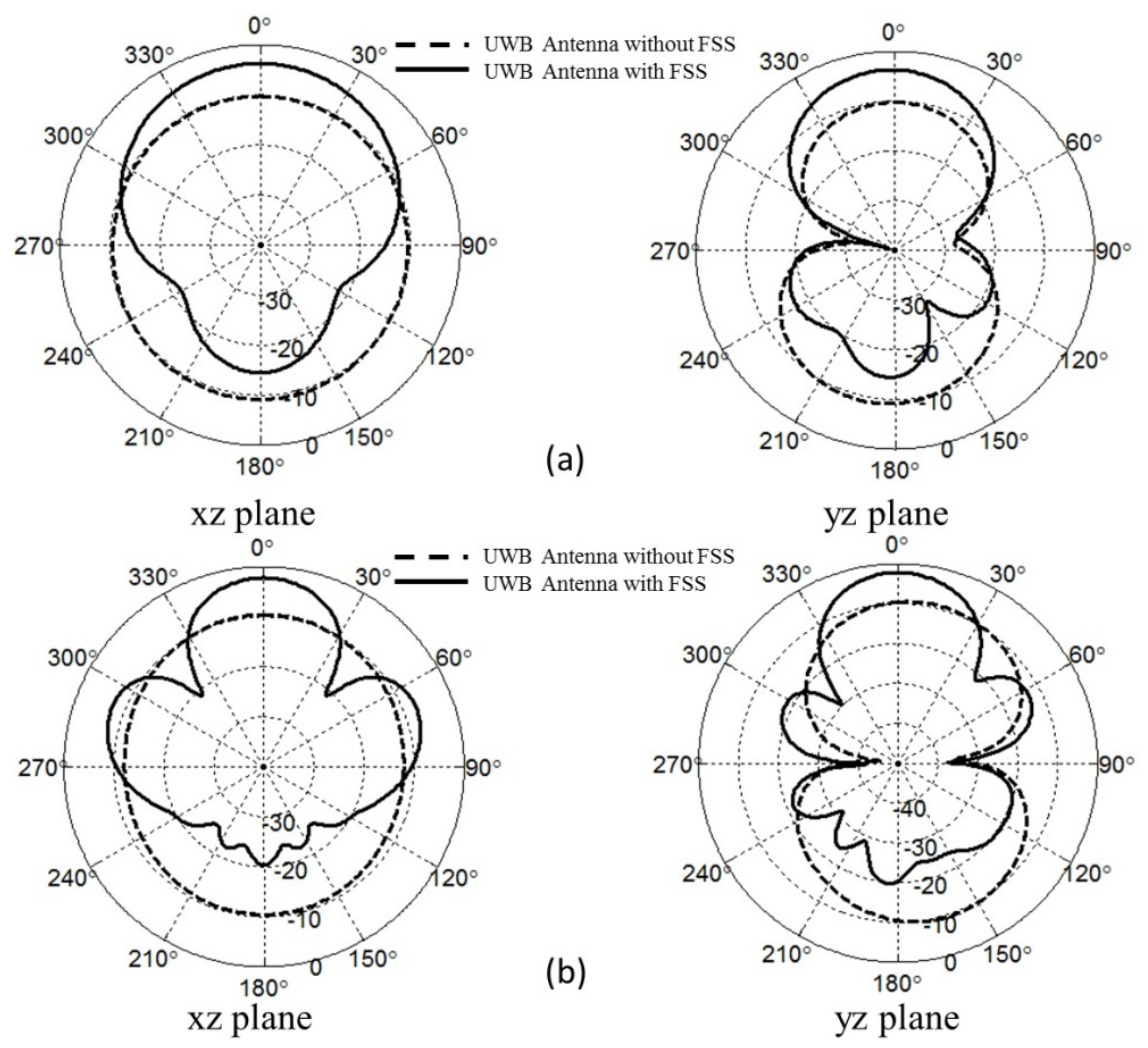

(b)

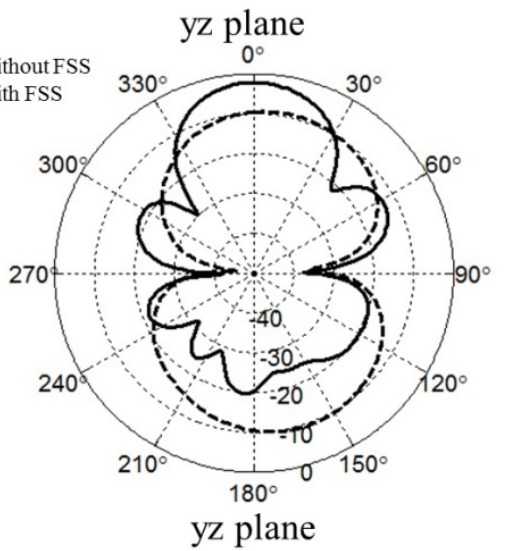

Fig. 11. Measured radiation patterns of the UWB antenna with and without the FSS at (a) 3.5 $\mathrm{GHz}$ and (b) $7.5 \mathrm{GHz}$.

\section{CONCLUSION}

A novel FSS reflector with compact structure is presented. Electrical dimensions of the unit cell are only $0.14 \lambda \times 0.14 \lambda$, where $\lambda$ refers to the wavelength corresponding to the lowest operating frequency of $3 \mathrm{GHz}$, and yet it achieves stopband of $9 \mathrm{GHz}$ from 3-12 GHz. The main advantage of the presented FSS design is that stopband response over the entire UWB band is achieved using single dielectric layer. The gain enhancing ability of the FSS is experimentally demonstrated. Average gain of the presented UWB antenna is improved from $3.8 \mathrm{dBi}$ to $6.6 \mathrm{dBi}$ using the proposed FSS. The highest gain achieved by the antenna composite is $8.9 \mathrm{dBi}$. The antenna composite is suitable to find application in wireless communication, medical imagining and ground penetrating radar.

\section{REFERENCES}


[1] Catherwood , P. A; Scanlon, W. G.: Ultrawideband Communications-An Idea Whose Time has Still Yet to Come? IEEE Antennas and Propag. Mag., 57(2) (2015), 38-43.

[2] Jianxin, L.; Chiau, C.C.; Xiaodong, C.; Parini, C.G.: Study of a printed circular disc monopole antenna for UWB systems. IEEE Trans. Antennas Propag., 53(11)(2005), 3550-3554.

[3] Angelopoulos, E.S.; Anastopoulos, A.Z.; Kaklamani, D.I; Alexandridis, A.A.; Lazarakis, F.; Dangakis, K.: Circular and elliptical CPW-fed slot and microstrip-fed antennas for ultrawideband applications. IEEE Antenna Wireless Propag. Lett., 5(2006), 294-297.

[4] Cruz , R.M.S.; D’Assunao, A.G.; da F Silva, P.H.: A new FSS design proposal for UWB applications. Dig. iWAT, (2010), 1-4.

[5] Tahir, F. A.; Naqvi, A. H.: A Super wideband printed antenna with enhanced gain using FSS structure. 12th International Bhurban Conference on Applied Sciences and Technology (IBCAST), Bhurban (Pakistan), 2015.

[6] Tahir, F. A.: A novel single-layer frequency selective surface for gain enhancement of SWB Antenna. Microwave Opt Technol. Lett., 58 (2016), 2030-2035.

[7] Ranga, Y.; Matekovits, L.; Esselle, K.P.; Weily, A.R.: Multioctave frequency selective surface reflector for ultrawideband antennas. IEEE Antennas Wireless Propag. Lett., 10(2001), $219-222$.

[8] Kushwaha N.; Kumar, R.: Design of a compact CPW-feed asymmetric elliptical slot ultrawideband antenna for high gain. Microw. Opt. Technol. Lett., 57 (2015), 314319.

[9] Ranga , Y.; Matekovits, L.; Weily, A.R.; Esselle, K.P.: A constant gain ultra-wideband antenna with multi-layer frequency selective surface. Progress In Electromagnetics Research Letters, 38(2013), 119-125.

[10] Kushwaha, N.; Kumar, R.; Oli, T.: Design of a high gain ultra-wideband slot antenna using frequency selective surface. Microwave Opt Technol Lett., 56 (2014), 12741277.

[11] Kushwaha, N.; Kumar, R.; Ram Krishna, R.V.S.; Oli, T.: Design and analysis of new compact UWB frequency selective surface and its equivalent circuit. Progress in Electromagnetics Research C, 46(2014), 31-39. 